\section{Michigan Technological

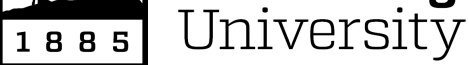

Michigan Technological University Digital Commons @ Michigan Tech

3-30-2013

\title{
The Effects of Snowfall on Solar Photovoltaic Performance
}

Rob W. Andrews

Queen's University - Kingston, Ontario

Andrew Pollard

Queen's University - Kingston, Ontario

Joshua M. Pearce

Michigan Technological University

Follow this and additional works at: https://digitalcommons.mtu.edu/materials_fp

\section{Recommended Citation}

Andrews, Rob. W., Pollard, Andrew, \& Pearce, Joshua M. (2013). The effects of snowfall on solar photovoltaic performance. Solar Energy, 92, 84-97. http://digitalcommons.mtu.edu/materials_fp/27/ 


\title{
The Effects of Snowfall on Solar Photovoltaic Performance
}

\author{
Rob W. Andrews ${ }^{\mathrm{a}}$, Andrew Pollard ${ }^{\mathrm{a}}$, Joshua M. Pearce ${ }^{\mathrm{b}, *}$ \\ ${ }^{a}$ Department of Mechanical and Materials Engineering, Queen's University, Canada \\ ${ }^{b}$ Department of Materials Science and Engineering and Department of Electrical and Computer Engineering, Michigan Technological \\ University, USA
}

\begin{abstract}
Solar photovoltaic (PV) systems are frequently installed in climates with significant snowfall. To better understand the effects of snowfall on the performance of PV systems, a multi-angle, multi-technology PV system was commissioned and monitored over two winters. A novel methodology was introduced and validated with this system, which allows for the determination of snowfall losses from time-series performance data with correlated meteorological observations down to a 5-minute resolution. In addition, a new method for determining the probability distribution of snow deposition on a module from image data was developed. It was found that the losses due to snowfall are dependent on the angle and technology being considered and the effects of increased albedo in the surroundings of a PV system can increase expected yields, particularly in the case of high tilt angle systems. Existing methods for predicting losses due to snowfall were investigated, and were found to provide overly conservative estimates of snow losses. Overall the results show that the proper assessment of snow related losses can help improve system performance and maintenance. It is concluded that proper characterization of the snowfall effect on PV system performance can influence better systems optimization for climates experiencing snowfall.
\end{abstract}

Keywords: snow, photovoltaics, snow losses, snow albedo, time series analysis, snow loss prediction

\section{Introduction}

As the costs of solar photovoltaic (PV) systems continue to decline the levelized cost of solar electricity becomes increasingly attractive in a widening group of areas throughout the globe including those in sub-optimal latitudes and climates (Branker et al. 2011a). As such, in 2009 nearly three-quarters of PV resources were installed in countries that experience some amount of snowfall, namely Germany, Czech Republic, Japan, and most recently Canada (SolarBuzz, 2010). Depending on the orientation and tilt angle of the PV modules and meteorological factors, previous studies have indicated that snow losses on a PV system can be as high as $15 \%$ for a low profile system in Truckee California to $0.3 \%-2.7 \%$ for a highly exposed 28 degree roof mount system in Germany (Townsend and Powers, 2011; Becker et al. 2008, Marion et al., 2005: Yoshioka et al. 2003: Yoshio et al., 1999; Ross, 1995, Brench, 1979). In order to optimize both the economic (Branker et al. 2011a b, Ren et al., 2009, Mondol et al., 2009) and environmental outcomes (Laleman et al., 2011: Kenny et al., 2010, Pearce, 2002, Nieuwlaar and Alsema, 1997) from PV systems (Parida et al., 2011), proper prediction of systems yields is critical and requires in-depth and

*601 M and M Building 1400 Townsend Drive Houghton, MI 49931-1295 906-487-1466

Email address: pearce@mtu.edu (Joshua M. Pearce ) accurate accounting of all loss mechanisms (Mani and Pillai, 2010, Thevenard et al., 2010). Therefore, a test site has been commissioned in Ontario, Canada to investigate this question, and the results from two years of study are presented. The purpose of this study is to provide a comparison of energy yields from a wide variety of technologies and module configurations to provide a better understanding of the effects of system design on snow related losses, gains and shedding. In addition, a novel methodology to determine snowfall losses from time-series data is introduced.

\section{Background}

Snowfall accumulation on modules is strongly affected by the ambient temperature, wind speeds, inclination from the horizontal, and surface properties (Pfister and Schneebeli, 1999). At temperatures below $-3^{\circ} \mathrm{C}$ a snow crystal that impacts the surface of a module will bounce on the surface. As the temperature decreases the possibility of this bouncing increases, and as the angle of the module to the horizontal increases, the possibility of this bouncing causing the particle to slide along the surface increases. In addition, the hydrophobicity of the surface has been shown in some cases to increase the propensity of the snow particle to slide on the surface (Kako et al. 2004). At temperatures above $-3^{\circ} \mathrm{C}$ bouncing action is reduced, and the snow particle will 
tend to adhere immediately to the module face (Pfister and Schneebeli, 1999). Once the particles adhere to the face of the module, cohesion between snow particles will cause the snow mass to increase on the module.

Once a layer of snow has accumulated on the face of a PV module, some light can still penetrate the snowpack and reach the PV module. This is an exponential relationship, which is described by Giddings and LaChappelle (Giddings and LaChapelle, 1961) and the Bouger-Lambert law. Both of these predict that approximately $20 \%$ of incident radiation will be available at $2 \mathrm{~cm}$ snow depth, and $3-4 \%$ is available at $10 \mathrm{~cm}$ depth. These correlations have been demonstrated empirically to be a reasonably good fit to experimental data (O'Neill and Gray, 1972, Curl et al., 1972). The light transmitted is primarily short-wave radiation, and thus does not necessarily align with an ideal spectrum for PV electricity production, which of course depends on the bandgap of the photovoltaic material; however, this transmitted light can be important for shedding phenomenon, which will be explained below.

An important property of snow residing on a module is its insulation properties as fresh snow can have a thermal conductivity as low as $0.04 \mathrm{~W} / \mathrm{mK}$, which is equivalent to that of fibreglass insulation (Ross, 1995). Therefore, the snow will act as an insulating layer, and protect the surface of the module from convective heat loss. This will allow the module to retain the heat generated from incoming radiation and conductive sources, which in turn increases energy transfer into heating the snow-module layer to produce a water layer that can promote snow sliding.

Snow shedding can occur in two major forms, either sheet sliding or pure melting. The clearing mode depends heavily upon the physical arrangement of the modules. For example, if there is room for the snow to slide it generally will; however, if the sliding process is impeded by physical obstructions (e.g. a close packed multi-row flat roof PV system) the snow cover will have to melt directly on the modules in order to clear.

\subsection{Module Control Volume}

Assume the module as a control volume, the energy influx to a snow-covered module can occur in three ways: diffusion of short wave radiation through the snow pack, albedo reflection to the exposed rear of the module, and conduction from other parts of the PV array that are not covered with snow. The amount of albedo reflection onto the rear of the modules can be 25\% (Ross, 1995) or more (Townsend and Powers 2011) of incident global radiation; however, this is highly dependent on the physical orientation of the modules. A ground mount system, such as could be seen in an industrial PV installation will typically have modules arranged in such a way as to have a large view factor between the rear of the module and the snow-covered ground and array. A residential roof mount will have virtually no albedo reflection to the rear of the module.

In addition, the emissivity of the rear face of the module will affect its ability to convert this reflected radiation to heat. A high spectral emissivity at the back of the module will allow the reflected radiation from the snow to heat the modules. Once the snow on the ground melts due to warmer temperatures, the ambient albedo will be reduced from $0.5-0.7$ to around 0.2 and therefore there will not be available a large amount of reflected radiation, and thus the module temperature will not be raised significantly in the summer. This effect was studied in detail analytically for a more complicated system utilizing a sealed convection chamber that increases the efficiency of albedo absorption (Ross, 1995).

\subsection{Previous studies of snow effects on PV systems}

There are notable studies on the effects of snowfall on PV systems. The first was performed in 1979 at the Natural Bridges National Monument and had an apparatus similar to that used in the present study. The author utilized a simple linear empirical correlation to determine expected PV output, and used this metric to determine snowfall losses. However, $56 \%$ of the data were discarded due to issues with the pyranometer being obscured by snow or data logger reliability issues. Thus, a yearly estimation of snowfall loss was not determined; however, the following energy loss averages were determined from the remaining data and are presented in Table 1

Table 1: Daily loss predictions from 1979 study Brench 1979.

\begin{tabular}{ccc||cc} 
& $30^{\circ}$ module angle & \multicolumn{2}{c}{$40^{\circ}$ module angle } \\
\hline \hline Snow depth & $>1 "$ & $<1 "$ & $>1 "$ & $<1 "$ \\
Daily loss & $45 \%$ & $11 \%$ & $26 \%$ & $5 \%$
\end{tabular}

A theoretical study of snow shedding was performed by Ross in 1995, with the goal of improving the battery charging performance of remote sites. A new passive melting technology, based on the reflection of light onto the rear surface of the module was developed, and $\mathrm{C}++$ code was developed to aid in the development of this technology (Ross 1995). The code predicts the temperature of a module as it is covered with snow, and is based on the assumption that when the module reaches a temperature of $0^{\circ} \mathrm{C}$ the module will begin to clear. While this assumption is dubious, the simulation lead to some interesting conclusions. For example, it predicted that a light dusting of snow $(<3 \mathrm{~cm})$ will actually increase the rate of snow shedding from the module as the added insulation by this layer will reduce heat losses from the 
module, which allows it to more rapidly reach a higher temperature.

Another study was performed in 2008 using six years of data from the New Munich Trade Fair Centre (Becker et al. 2008). Snowfall losses range from $0.3 \%-2.7 \%$ from 1999 to 2006, however, the methodology for determining these losses was not specified. Interestingly, snow clearing can be observed to occur from module temperatures of $+30^{\circ} \mathrm{C}$ to $-10^{\circ} \mathrm{C}$, with the higher module temperatures occurring at higher insolation. This finding invalidates the assumptions used in the modelling performed by Ross that assumed that snow would clear from a module once the temperature reaches $0^{\circ} \mathrm{C}$.

An attempt to utilize satellite imaging to identify times when a PV plant is covered with snow has been documented. There were two major error sources from this form of detection (i) false alarm, where satellite imagery shows the plant to be uncovered, when it is in fact covered and (ii) under prediction, stemming from an overestimation of times of snow cover. These two error mechanisms had values of $26 \%$ and $23 \%$ respectively, which indicated the probability of errors in prediction occurring from this system. In addition, there was a low data availability of around $65 \%$ which could limit the use of this technique as a consistent monitoring methodology. (Wirth et al. 2010) However, it was shown to be a potentially useful tool for monitoring the performance of distributed systems when local irradiation monitoring is not available.

Most recently, data from two test sites were obtained, one which had a set of modules that were consistently cleared of snow, and the other was an operating fixed tilt system with no module clearing regimen (Townsend and Powers, 2011). These sites were located in Truckee ,CA, which receives on average $5 \mathrm{~m}$ (200in) of snow per year. Snow losses were recorded on a monthly basis, and ranged up to $100 \%$ of expected yield for a flat low profile system. On an annual basis losses were found to be $6 \%$ for the fixed tilt system, and 13\%, $17 \%$, and $26 \%$ for a low profile system of angles $39^{\circ}, 24^{\circ}$, and $0^{\circ}$ respectively. A model was developed to estimate snow losses based on meteorological data, which displayed some ability to predict monthly energy loss from a system, and it was applied to other locations that experience some level of snowfall, however it has not yet been validated.

The current study overcomes the limitations of the previous snow studies by providing novel measurement methodologies and multiple co-located module technologies and orientations, and attempts to validate the work of Townsend and Powers (Townsend and Powers, 2011).

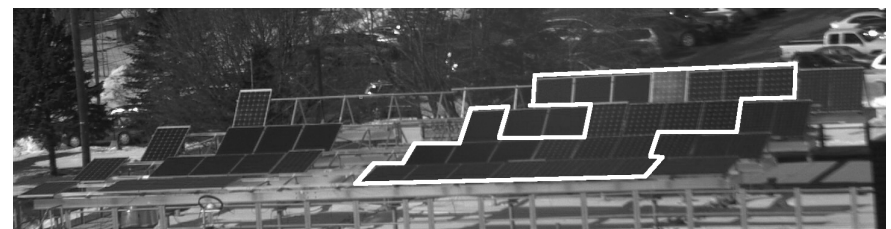

(a) 2011

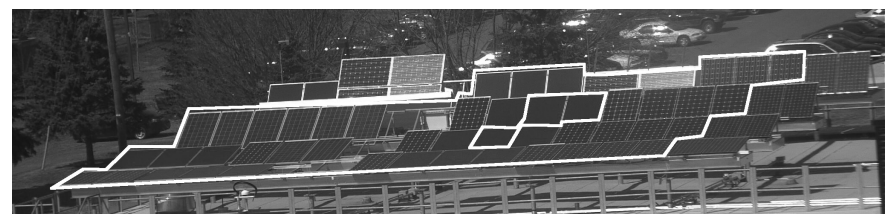

(b) 2012

Figure 1: OSOTF in the spring of 2011 and 2012. The modules outlined in white were included in the quantitative analysis, and all modules were included in the visual analysis

\section{Methodology}

A system was developed to test the effect of snowfall on PV modules oriented at a variety of tilt angles with a variety of technologies and front coatings. The system, called the Open Source Outdoors Test Field (OSOTF), was designed on open source principles (Pearce et al. 2012). All system documentation, commissioning reports and system data are available freely in the public domain 1 .

A total of 70 modules of both amorphous silicon (a-Si:H) and crystalline silicon (c-Si) are monitored for short-circuit current $\left(I_{s c}\right)$ and back temperature at 5 -minute intervals, and a full meteorological station is co-located at the roof including secondary standard heated and ventilated pyranometers (Pearce et al. 2012). The modules used in this study were set at angles of $5^{\circ}, 10^{\circ}, 15^{\circ}, 20^{\circ}, 40^{\circ}$, and $60^{\circ}$. There are multiple modules at each angle, and each represents a module that has been specifically modified with a surface treatment or is from a specific manufacturer. Future publications will look specifically at the effects of these surface treatments on the performance of the modules. An exception is the panels installed at $30^{\circ}$ which are all nominally identical panels. Figure 1 shows a layout of the test site and the relative locations of the modules. The site was expanded over the summer of 2011, and the modules that are included in each year of study are shown as those outlined in white. It should be noted that the spacing of the modules was maintained such that inter-row shading losses would be the same for all rows.

For the two winters being considered, $\left(I_{s c}\right)$ was used as a representative performance metric. $I_{s c}$ is heavily

\footnotetext{
${ }^{1}$ The live web cam is accessible at snowstudy.ati.sl.on.ca the design and operations documentation is available at ww. appropedia.org/SEARC_OSOTF_Design_and_Operations_Manual and the data stream is available at searckingston.ati.sl.on.cal selectData.php
} 


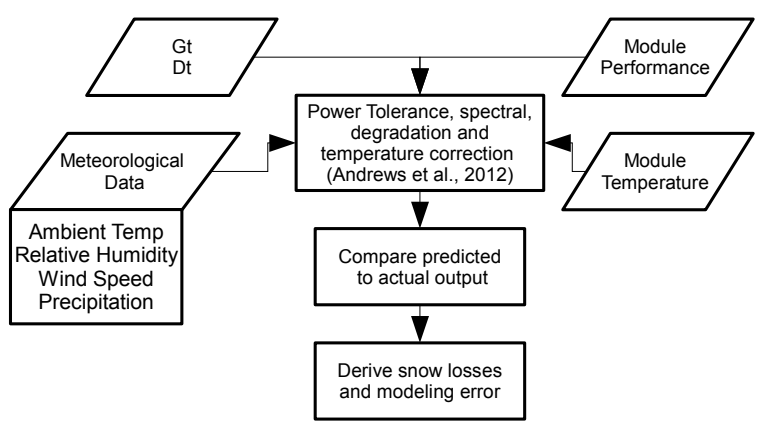

Figure 2: Data processing flowchart, $G_{t}$ and $D_{t}$ represent the time series of measured global and diffuse irradiation respectively. Module performance in this case is defined as a timeseries of $I_{s c}$.

influenced by the amount of effective irradiation (including spectral effects) that reaches the cell. At constant temperature $I_{s c}$ is related linearly to effective irradiation under no or low levels of concentration (Wolf and Rauschenbach, 1963, Fabero and Chenlo, 1991) and is only comparatively weakly affected by temperature, which is corrected during system modelling. Therefore a change in the $I_{s c}$ will have a proportional change on the power output of a module, as it represents the level of light reaching the modules, making it an appropriate performance metric, while effectively isolating against the effects of temperature on the results.

\subsection{System Modelling}

A baseline data set of a PV system performance is first required against which its actual performance under the effects of snow may be compared. In order to do this, a methodology was developed to accurately predict the $I_{s c}$ of a PV module based on meteorological measurements (Andrews et al. 2012). This was adapted from the Sandia performance model (King et al. 2004) to be applicable to high temporal resolutions.

The general analysis methodology used here is given in Figure 2, The goal is to apply high-resolution modelling techniques to predict the $\hat{I_{s c}}$, which is the modelled short circuit current. Comparison of the predicted to the actual output enables the effects of snow to be determined. A useful metric for identifying these effects is the modelled output ratio $\left(M_{O R}\right)$, which is defined as:

$$
M_{O R}=\frac{I_{s c}}{\hat{I_{s c}}}
$$

Albedo was assumed to be a constant value of 0.7 if snowfall was present and 0.2 if not, which are relatively standard values (Warren, 1972; Gardner and Sharp, 2010 Thevenard 2006 Therefore, any albedo

\footnotetext{
${ }^{2}$ Recent work has shown, however, that higher values for albedo are likely appropriate for snow, when the spectral sensitivity of the receiving surface is considered (Andrews and Pearce 2012)
}

reflection which is effectively greater than this amount (Andrews and Pearce, 2012) would lead to the modules over-producing current relative to their expected outputs. Thus, increased albedo reflection is measurable using this methodology.

\subsection{Identifying the Snow Effect}

Once the system has been modelled, a time series of so-called "synthetic days" can be assembled. The goal of these synthetic days is to model the output of the PV module without the addition of external, stochastic factors such as dust and snow accumulation. The yearly snow effect is defined as the summation of the difference between the actual and synthetic output, and the error associated with this measure is the Mean Bias Error (MBE) (defined in Equation 2 of the model applied to an entire year of collected data.

$$
M B E=\frac{\overline{\hat{I_{s c}}}-\overline{I_{s c}}}{\overline{I_{s c}}}
$$

\subsubsection{Determining Module Clearance}

Another important metric to account for snowfall effects is the time required to clear a module after a snow event. A filtering algorithm was employed to identify periods when modules were covered and cleared of snow. First, for each module, marker points which matched the following characteristics were identified:

$$
\begin{aligned}
& \text { i. } M_{O R}(t) \ldots M_{O R}(t+20 \mathrm{~min})<70 \% \\
& \text { ii. }\left|I_{s c}-\hat{I_{s c}}\right|>\frac{I_{s c o}}{12}
\end{aligned}
$$

Where $I_{s c o}$ is the module rated $I_{s c}$ at $1000 \mathrm{~W} / \mathrm{m}^{2}, 25^{\circ}$, and a spectrum of AM1.5G (STC conditions). This point identifies a location where there is a clear deficiency between actual and modelled output, which is persistent over at least 20 minutes. This eliminates variations in cloud cover, short term shading and other effects (which are presumed negligible). This marker point represents a clearly identifiable loss due to snowfall; however, is not necessarily the beginning of snow coverage on a panel. The beginning of snow coverage is then located by searching backwards from the identified point for the point where $G_{t}<10 \mathrm{~W} / \mathrm{m}^{2}$ (Global Irradiation) or $M_{O R}(t) \ldots M_{O R}(t-20)>85 \%$ with the assumption being that either the nearest morning, or point where the output ratio reaches near to ideal, indicates the beginning of the snow coverage.

To determine the point at which the module is assumed to be clear a forward search locates the point where

$$
\begin{aligned}
& \text { i. } M_{O R}(t) \ldots M_{O R}(t+20 \mathrm{~min})>85 \% \\
& \text { ii. } M_{O R}(t) \ldots M_{O R}(t+20 \mathrm{~min})<120 \%
\end{aligned}
$$

\section{OR}

$$
\begin{aligned}
& \text { i. }\left|I_{s c}(t)-\hat{I_{s c}}(t)\right| \ldots \mid I_{s c}(t+20 \text { min })-\hat{I_{s c}}(t+20 \text { min }) \mid< \\
& \quad \frac{I_{s c o}}{35} \\
& \text { ii. AirMass }<4
\end{aligned}
$$


The first set of requirements locates the point where the panel has returned to operation within $85 \%$ of predicted output, which indicates that the panel has substantially cleared. The upper threshold on performance ratio is implemented to provide stability in the cases where the output magnitude is small (such as at the beginning and end of the day) which can cause asymptotic behaviour in the performance ratio. The second set of conditions is utilized to identify points where, due to low light levels, the use of the modelled output ratio characteristic becomes unstable, and Air Mass represents the thickness of air through which the radiation must travel, normalized by the actual atmospheric thickness. Using this algorithm, each point where the module is obscured by snow can be identified, and the length of time that it takes to clear can be measured.

\subsection{Image Analysis}

Time-lapse digital photography was also taken at five minute intervals to track the accumulation and shedding of snow on the modules. Each photograph was imported and aligned to a sup-pixel accuracy using a Fourier transform based luminance optimization algorithm to a baseline image (Guizar-Sicairos et al. 2008) to eliminate effects of camera vibrations and creep. Each frame was then converted to grayscale and thresholded using an unbounded Otsu Adaptive algorithm (Nobuyuki, 1979) to identify snow on modules. Each module in the frame was then isolated, and a three dimensional histogram that indicates the relative likelihood of snow accumulating at a point on the module was constructed by summing through each pixel of the module. A flowchart illustrating each stage of this process is shown in Figure 3. The resolution of the camera was upgraded halfway through the winter of $2010 / 2011$, and therefore two separate graphics were produced, one from the low resolution dataset and one from the high resolution set, as the module histograms were incompatible.

\section{Presentation of Results}

The main results from this study are shown in Figure 4 and 5, which demonstrate as a percentage of total yearly production, the magnitude of losses due to snowfall in the winters of 2010/2011 and 2011/2012. Measurements for the winter of $2010 / 2011$ began on January 7, 2011, however as can be noted from Table 2 there was not a significant accumulation of snow earlier in the year, and therefore the data may be considered representative for the year. Because of the small magnitude of the total snow in the winter of 2010/2011 at the test site compared to historical averages, the annualized losses due to snowfall are not statistically significant. However, it is still possible to utilize information related to individual snow events to characterize snow clearing events.

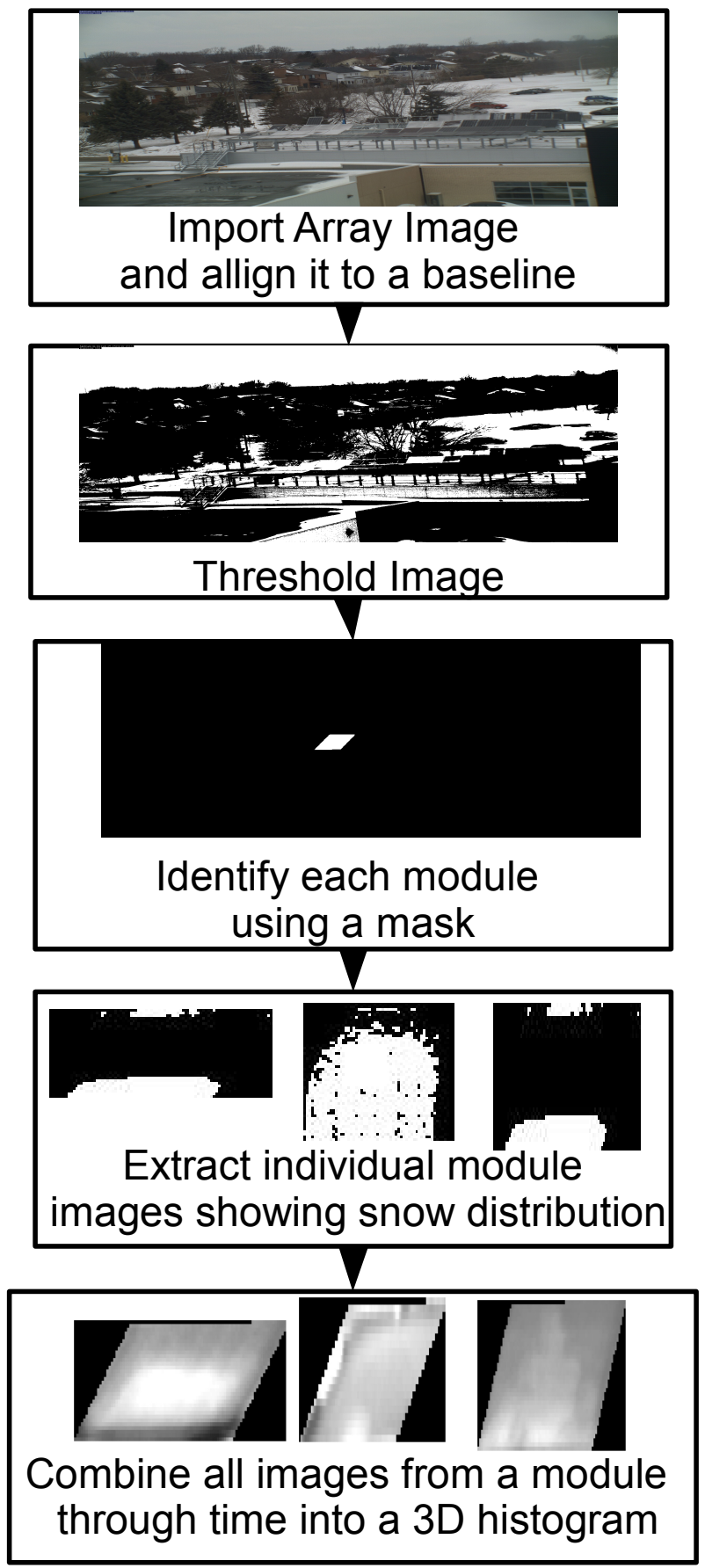

Figure 3: Data processing for image analysis flowchart 
Table 2: Average monthly snowfall accumulation and temperature from the Kingston Climate station.

\begin{tabular}{ccccccc} 
& \multicolumn{2}{c}{ Yearly total } & \multicolumn{2}{c}{ Dec } & \multicolumn{2}{c}{ Jan } \\
Year & $\mathrm{cm}$ & ${ }^{\circ} C$ & $\mathrm{~cm}$ & ${ }^{\circ} C$ & $\mathrm{~cm}$ & ${ }^{\circ} C$ \\
\hline \hline $2010 / 2011$ & 58 & -4.2 & 2 & -3.8 & 30 & -9.3 \\
$2011 / 2012$ & 49 & -1.0 & 8 & -0.5 & 22 & -3.9 \\
\hline \multicolumn{3}{c}{ Historical Avg. } & \multicolumn{2}{c}{ Feb } & \multicolumn{2}{c}{ Mar } \\
Year & $\mathrm{cm}$ & ${ }^{\circ} \mathrm{C}$ & $\mathrm{cm}$ & ${ }^{\circ} \mathrm{C}$ & $\mathrm{cm}$ & ${ }^{\circ} \mathrm{C}$ \\
\hline \hline $2010 / 2011$ & \multirow{2}{*}{180.9} & -1.7 & 17 & -6.7 & 9 & -1.1 \\
$2011 / 2012$ & & & 12 & -2.2 & 2 & 1.6
\end{tabular}

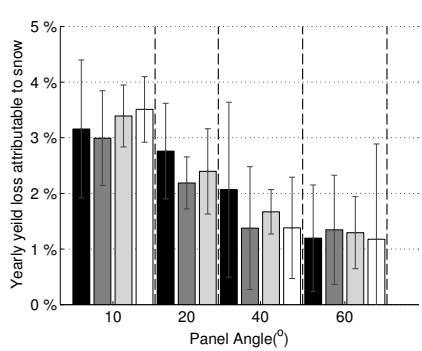

(a) Crystalline

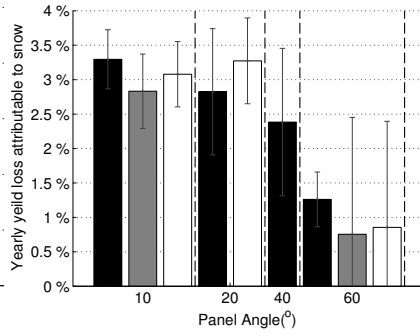

(b) Amorphous
Figure 4: Losses attributable to snow in the winter of $2010 / 2011$, the different shaded bars represent a different module manufacturer or surface treatment

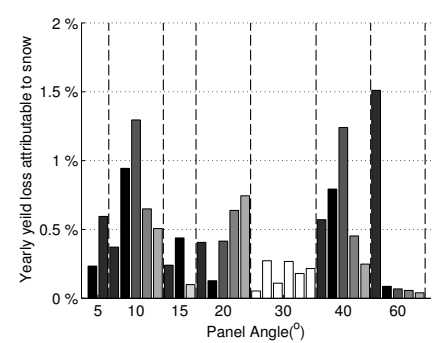

(a) Crystalline

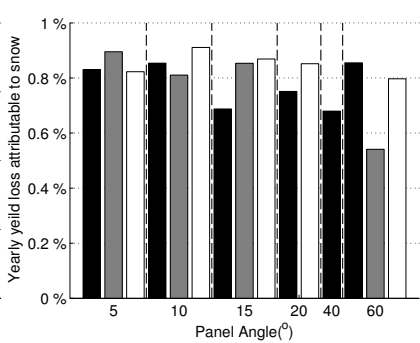

(b) Amorphous
Figure 5: Losses attributable to snow in the winter of 2011/2012, the different coloured bars represent a different module manufacturer or surface treatment. Error bars are not shown on this plot, as they are greater in magnitude than the measured results.

Figure 6 presents surface plots of the difference between actual and modelled daily $I_{s} c$ production. The height and duration of the peaks in the first winter the snow losses are dominant; however, in the second, much milder, winter they are less pronounced.

To put these snowfall losses in perspective, Table 2 gives information on the snow accumulation measured at a nearby weather station, Kingston Climate (EnvironmentCanada, 2012), for the period of the study and compared it to historical norms.

\subsection{Time to clear snow from cell surface}

Another method to identify the effects of snowfall on modules is the time that it takes to clear the surface. Data showing the mean time to shed for each module is

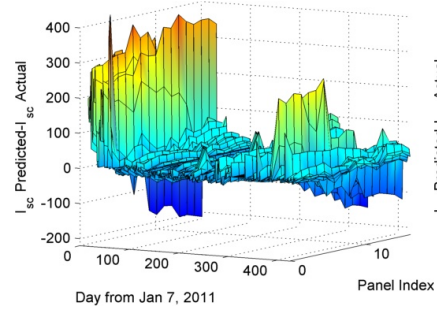

(a) Crystalline

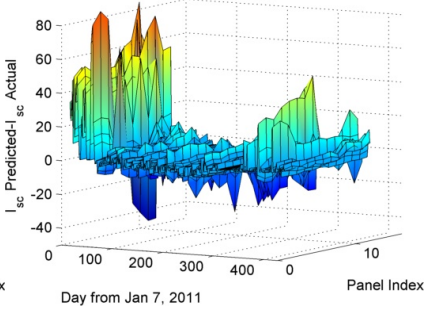

(b) Amorphous
Figure 6: A summary of daily module losses from January 7,2011 to March 9,2012, positive represents module under production. a and b show a top view of c-Si and a-Si:H, respectively.

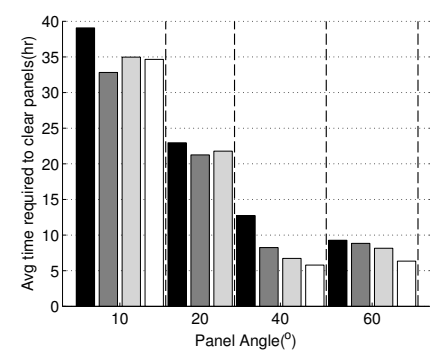

(a) Crystalline

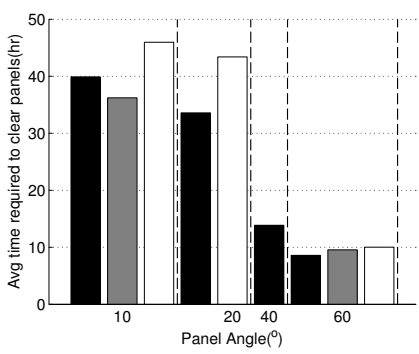

(b) Amorphous

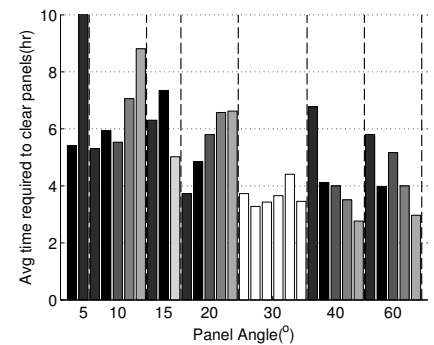

(c) Crystalline

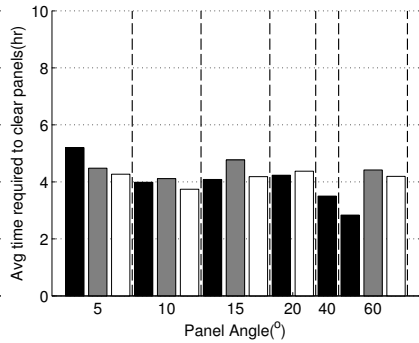

(d) Amorphous
Figure 7: Mean time to clear for c-Si, (a) and (c) and a-Si:H, (b) and (d) for the winter of 2010/2011 (a),(c) and 2011/2012 (b),(d) respectively. The colour of the bar represents a module from a specific manufacturer

shown in Figure 7, and is further expanded into box plots representing the entire dataset in Figure 8. These box plots show the variability in each dataset, with the thick box representing the lower and upper quartiles, the central dot representing the median, the thin lines showing the extent of the largest and smallest values in the set, and any isolated points representing outliers from the dataset. In addition, Figure 9 shows the correlation between module angle, temperature and atmospheric relative humidity and shedding times.

To demonstrate how these shedding times were derived, a selection of time series data which demonstrated the differences in shedding profiles for the various modules is shown in Figure 10 . 


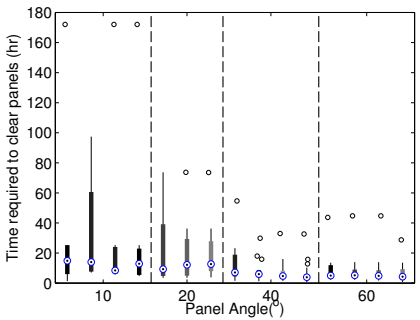

(a) Crystalline

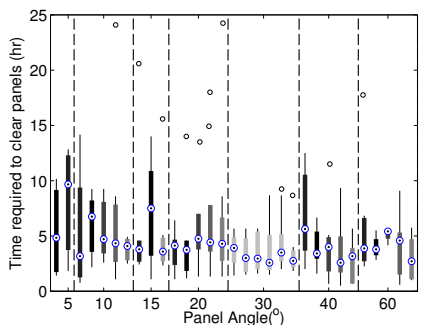

(c) Crystalline

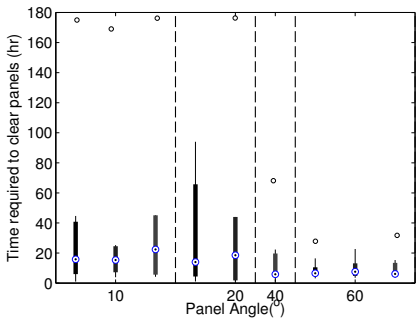

(b) Amorphous

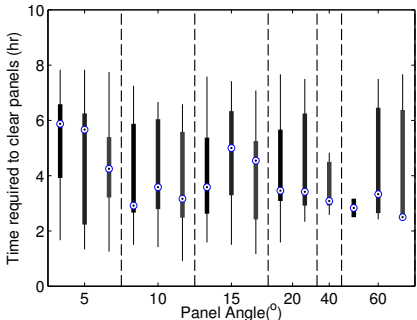

(d) Amorphous
Figure 8: Box plots representing all recorded shedding events for c$\mathrm{Si}$, (a) and (c) and a-Si:H, (b) and (d) for the winter of 2010/2011 (a),(c) and 2011/2012 (b),(d) respectively. The colour of the bar represents a module from a specific manufacturer

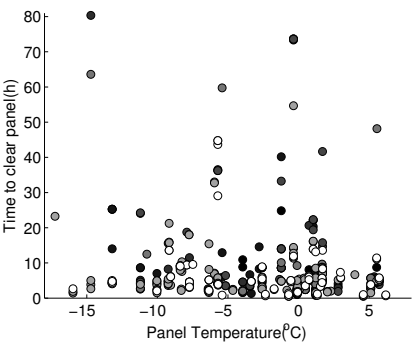

(a) Crystalline

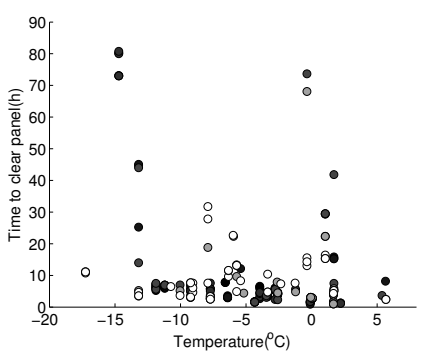

(c) Amorphous

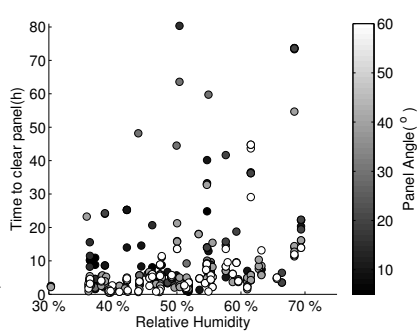

(b) Crystalline

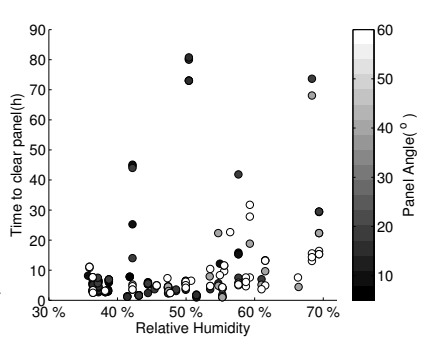

(d) Amorphous
Figure 9: Correlation of the time to clear for c-Si,(a) and (b) and a-Si:H (c) and (d) modules to average daily temperature and relative humidity, for the winter of 2010/2011 (a, c) and 2011/2012 (b, d) respectively

\subsection{Image analysis}

The results of the image analysis are shown in Figure 11, which represents a three dimensional histogram of snow accumulation on each module. This figure indicates areas where snow is most likely to collect on the surface of a module. The colour scale for these

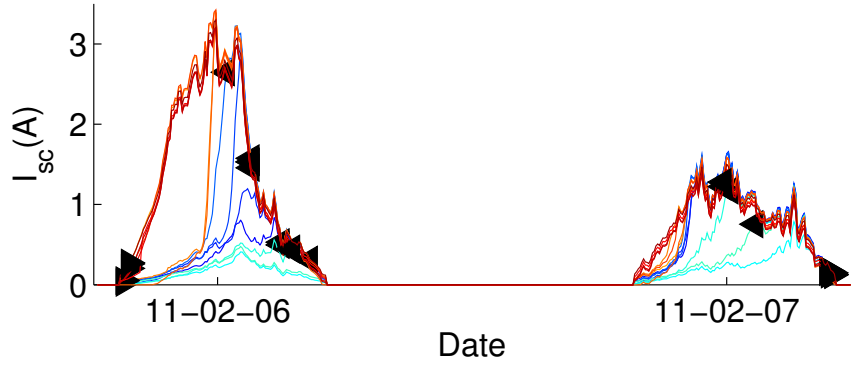

(a) February 2011

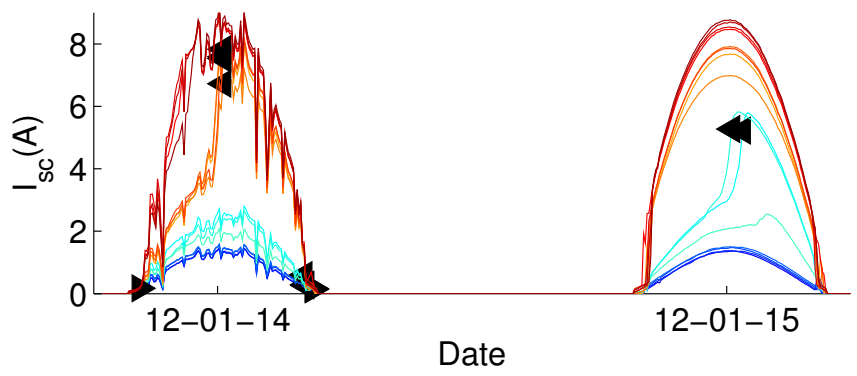

(b) January 2012

Figure 10: Time series showing snow shedding over two days

figures is based on the median of snow intensity from each module, therefore a darker red colour represents a higher probability of snow accumulating in this area, but does not necessarily represent a higher total accumulation of snow as compared to other modules.

\subsection{Application of existing snow loss algorithms}

The correlation suggested by Townsend (Townsend and Powers, 2011) was applied to the collected dataset, using meterological data collected on site or taken from the Kingston Climate station EnvironmentCanada, 2012) and a value of $\gamma=1$. The results of its application to the output of the modules tested in the winter of 2010/2011 are shown in Figure 12 .

\section{Analysis and Discussion}

From the given data some inferences about the nature of the effect of snowfall on PV systems can be derived. It should be noted initially that because of the low magnitude of these effects, in some cases the results are not statistically significant. The error for each estimation has been derived from the MBE of the underlying model used to predict the snowfall losses, assessed during the period where no snowfall was present. Though this modelling technique has a high degree of accuracy $(<1 \%$ in many cases) it is still in some cases of the same order of magnitude of the snowfall effect, especially in the second measured (mild) winter. 


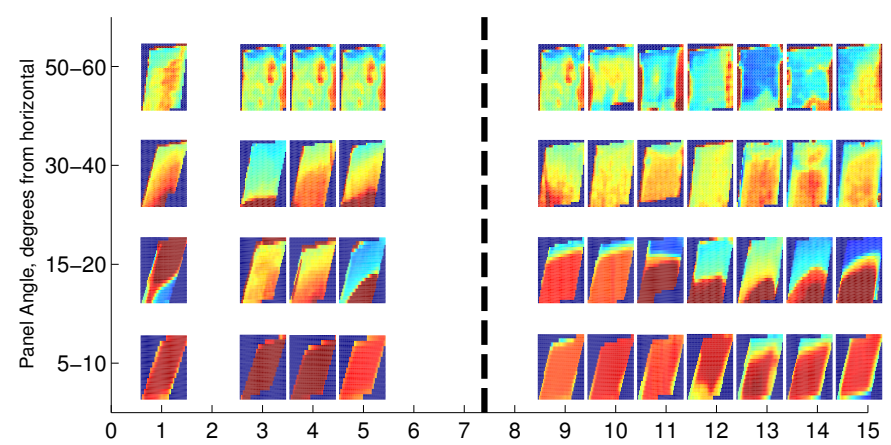

(a) January 2011

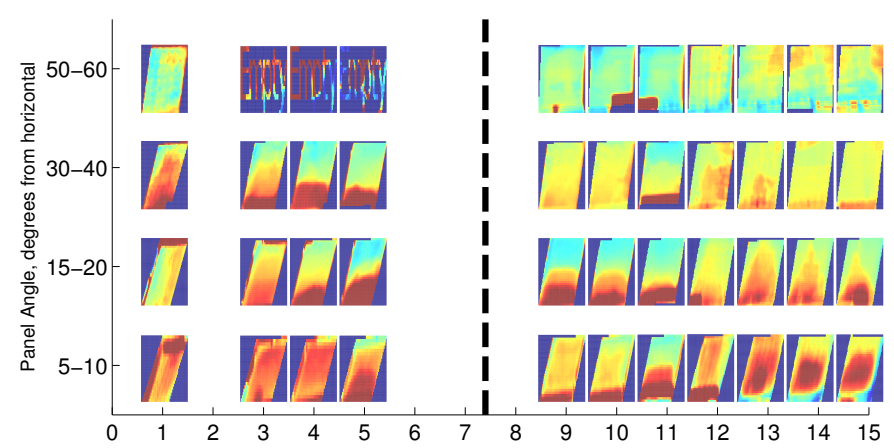

(b) Feb-March 2011

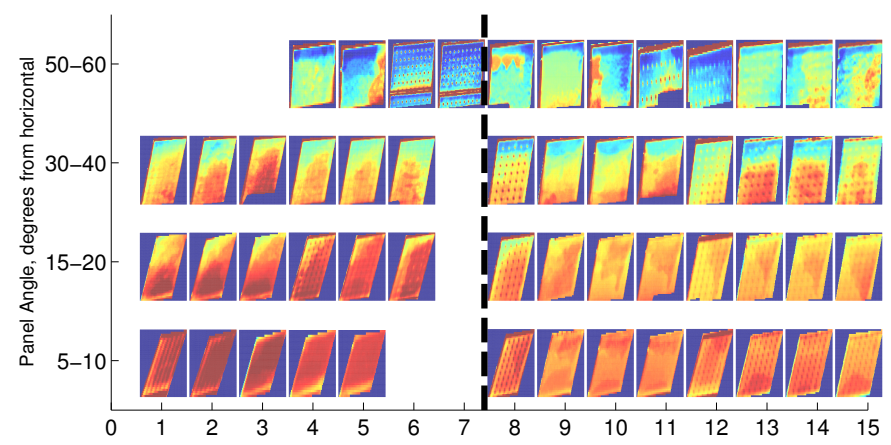

(c) Winter $2011 / 2012$

Figure 11: Image analysis results for three sections of time-lapse photos. Each module is scaled by the median of its intensity values, thus the gradients do not represent the magnitude of coverage, rather the normalized distribution on the surface of the module. Each row consists of modules at two angles, which are labelled on the y-axis and divided by the dashed line.

\subsection{Albedo Effects}

From the analysis of Figure 6 it can be seen that the effects of snowfall on the performance of a PV device is not always negative and could be used to optimize system design in certain climates. Because of the increased view factor of the modules with the ground at higher tilt angles, the ambient albedo will tend to improve the performance of higher angle modules, which may mask the true snowfall losses when long term averages are taken. Therefore Figure 13 shows the magnitude of this albedo effect on the performance of the modules, as a percentage improvement of yearly yield over that with

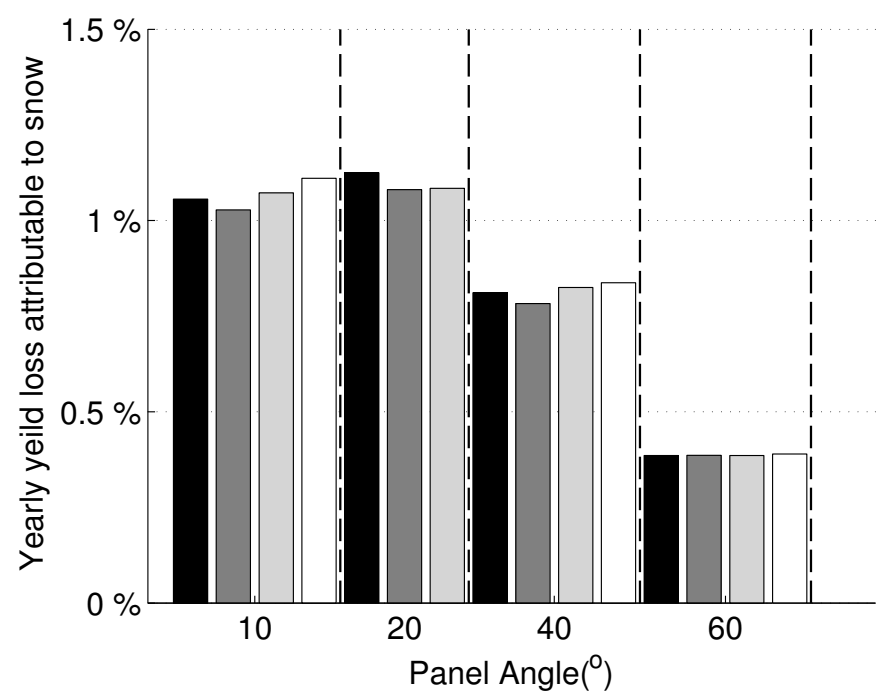

Figure 12: BEW algorithm applied to the output of modules studied for the winter of 2010/2011, showing predicted yield losses attributable to snow. The colour of the bar represents a module from a specific manufacturer

the expected albedo value of $70 \%$. As can be expected the albedo effect increases with module inclination angle, which is due to the increased view factor from the module to the snow surface. An explanation for the higher average level of albedo is given in Andrews and Pearce, 2012), which describes that snow albedo, which is spectrally weighted to the response of a module, will have a higher effective albedo than would be expected from fully spectrally integrating the reflectivity of the surface.

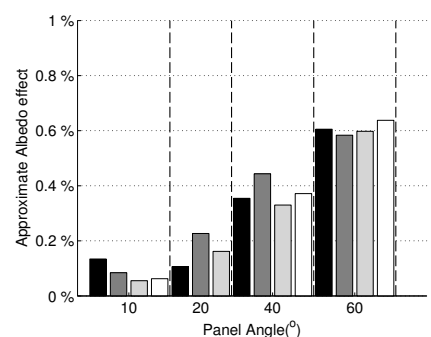

(a) Crystalline

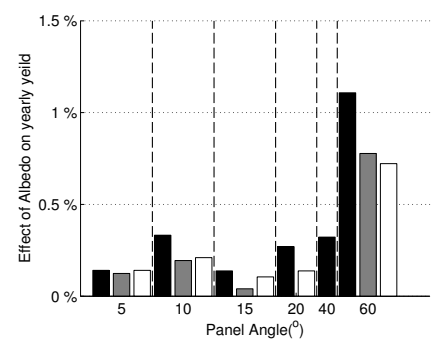

(c) Amorphous

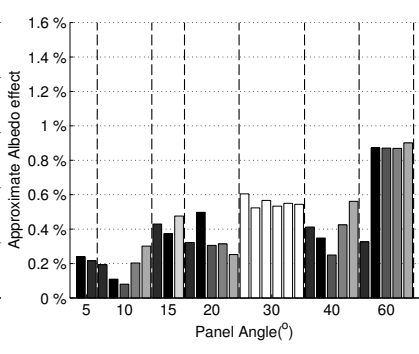

(b) Crystalline

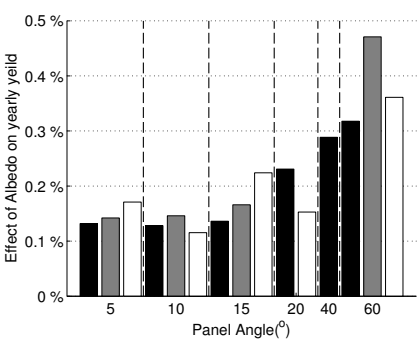

(d) Amorphous
Figure 13: Gains in performance attributable to snow albedo for c-Si and a-Si:H modules from both winters. The colour of the bar represents a module from a specific manufacturer 


\subsection{Angular dependence}

Overall, it can be seen that losses due to snowfall tend to decrease as module angle increases, and the same trend is apparent in the observed shedding times. However, in the second winter this angle dependence is less pronounced, both in the shedding times and in the energy yields. A possible explanation is because of higher average temperatures during the winter, the main shedding mechanism was melting rather than sliding of a snow sheet. Thus, the effects of gravity would be less prominent in this form of shedding mechanism, and this effect is investigated more thoroughly with the image analysis results.

In analysing the box plots of shedding times presented in Figure 8 it can be seen that in the first winter, the variability of shedding times tends to decrease as the panel angle increases. Notably, the position of the upper bound outliers shows a clear angular dependence, indicating that lower angles are more likely to have on average greater times to clear, in addition to a higher likelihood of being covered for an extended period of time, beyond what would be expected from the statistical distribution.

\subsection{Snowfall loss correlations}

The correlation of shedding times to daily average temperature and relative humidity given in Figure 9 indicate some weak trends. It appears that a higher relative humidity would tend to increase the residence time of snow on a module. Shedding events under 24 hours lower module temperatures can be seen to increase shedding times. Generally, however it can be observed that the shedding of snow from the surface of a module is a complex phenomenon that is not easily predicted from individual atmospheric variables. However, it can be noted that snow shedding occurs at module temperatures as low as $-15^{\circ} \mathrm{C}$, as was also seen in (Becker et al. 2008 ).

To investigate the use of exiting algorithms to predict the effects due to snowfall, the methodology introduced by Townsend was also applied to the meteorological data from the winter of $2010 / 2011$, and was shown in Figure 12. It was found that this algorithm tended to under-predict the effects of snowfall on the system. Because of the vastly different snowfall accumulations between the site where the model was developed and the present site, such variation probably may be expected. This methodology could be a useful method of conservatively determining the yearly snowfall losses.

\subsection{Accumulation of snowfall on a module}

The different methods of shedding can be seen in Figure 11 over the two years of study. It can be seen that in the winter of $2010 / 2011$ angles from $15^{\circ}$ to $40^{\circ}$ tend to display a gradient of snow accumulation, with the snow more likely to remain at the base of the module. This effect has been observed in previous studies, and indicated that the snow sheets that slide off the modules are obstructed by the bottom edge of the modules. At angles of $10^{\circ}$ and below, depending on the time of year and module, gradients are still observable. Snow accumulation, however, is generally more evenly distributed over the whole face of the module, indicating that snow is not sliding from the face of the module but is rather melting into its face. Interestingly, for modules 13, 14 and 15 in Figure 11.b snow is most likely to accumulate in the centre of the module, and there is not the same bottom edge accumulation as seen in other modules at the comparable angle. Across all winters, it can be seen that modules at angles of $50^{\circ}$ and $60^{\circ}$ have a bias of snow accumulation towards the top of the module, and is variable over the face of the module than those at lower angles. Because these modules are more exposed to ambient winds, it is likely that the added momentum of the snow impacting the module in those areas that are not sheltered from the wind by the row in front will give greater adhesion of the snow to these areas of the modules. Also, because the higher angle modules clear more quickly than their lower angle counterparts, the effects of a sheet of snow covering a portion of the module are less pronounced.

In the winter of $2011 / 2012$, it can be seen that though shedding gradients are still present, the distribution is more even over the face of the module. Due to the faster speed of clearing, and higher ambient temperatures at the time of snowfall in this year, it can be seen that the main method of module clearing is in melting, rather than sheet sliding.

\subsection{Effects on module performance}

As can be seen from all the visual data, there is a gradient in snow coverage that can be expected at most practical installation angles. Thus, in designing systems it is important to consider the orientation of diode protected strings within a module. With the current installation, the majority of c-Si based modules installed had a series of three overlapping bypass diodes, with strings parallel to the long edge of the module. Therefore, if a gradient of snow coverage was present on a portrait installed module (as the modules installed in the study were), photocurrent could not be generated as the entire string would be limited by its least producing (most snow covered element), which would magnify the effects of snow coverage. If the modules were installed in landscape, there is a chance that the snow gradient may impact the performance of the bottom string of cells, however, the upper unshaded strings would still be able to produce power.

It is also interesting to note the effects of module type on the distribution of snow cover. It can be seen in Figure 11 that the distribution of snow cover changes 
even between modules which are installed beside each other at the same angle. It can be seen from this that in a string architecture, uneven snow loading between modules in a string could cause string losses due to limitations of the most shaded module. However, this imbalance would cause a reverse bias current through the most affected module, which would increase its temperature and may promote snow clearing. More work is required in order to determine the overall effects of uneven snow loading on string architectures.

\subsection{Effects on system payback}

The decrease in energy output due to snow coverage over the winter will have an effect on the financial performance of the system. Looking at the simple (zero debt) payback period as a metric of financial payback given as:

$$
S P B=\frac{C C}{E_{\text {Ideal }}(1-\epsilon)}
$$

Where $S P B$ is the simple payback period, $C C$ is the installed capital cost of the system, $E_{\text {Ideal }}$ is the ideal energy output of a system with no snow losses, and $\epsilon$ is the snow loss as a percentage of yearly energy yield. Thus, the ratio of $S P B$ of an ideal system to one experiencing snow losses is proportional to $\frac{1}{(1-\epsilon)}$. Thus, assuming an arbitrary but realistic 7 year payback period and the worst case measured yearly snow energy loss of $3.5 \%$, the payback time will be increased by approximately 13 weeks.

However, solar can now be considered to be a financial investment due to its growing recognition as a low-technical risk and long term asset Branker et al. 2011a). It is therefore more appropriate to use an investment metric such as Return on Investment(ROI), which more fully embodies the total benefits of long term solar investments (Pearce et al., 2009). Assuming a system lifetime between 25 and 50 years, and a base payback period of 7 years, the ROI of a system would be decreased by $0.56 \%$ to $0.50 \%$ (absolute) due to the potential effects of snowfall.

\section{Future work}

Overall, this study has shown the detailed effects of snowfall on the DC performance of photovoltaic modules. It should be recognized that the effects of snowfall are highly dependant on system topology, and future work should look into the effects of snowfall on various PV topologies. In addition, generalizable methods to predict the effects of snowfall on a PV system from routinely collected weather data should be created. Future work is also needed to investigate methods to mitigate snowfall losses such as surface coatings, texturing, or snow clearing systems. Finally, these models and methods must be evaluated into the future taking in account the effects of climate change on snowfall characteristics.

\section{Conclusions}

This study introduced a methodology that can be used to derive snowfall losses and time to clear of snow from a time series of module performance data, a metric commonly collected at PV installation sites. In addition, a methodology to analyse snow shedding patterns from image data was introduced, and showed the variability of snow distribution patterns depending on module type and orientation. Overall it was seen that snowfall will tend to settle in a vertical gradient on the surface of the module.

It was found that the losses due to snowfall are dependent on the angle and technology being considered. Over the two years studied, which had low levels of snowfall when compared to historic data, the losses ranged from $3.5 \%-1 \%$ of expected yearly yield for sites in south-eastern Ontario. It was also found that the effect of increased spectrally responsive albedo can cause an increase of approximately $1 \%$ over projected yields on modules with higher inclinations from the horizontal. An attempt was made to correlate the time required to shed snow to module temperature and relative humidity, and though some weak trends are apparent: that a lower temperature and higher relative humidity will tend to increase the time to shed, they were not significant. Overall it was found that the proper assessment of snow related losses can help improve system performance and maintenance. In addition, proper characterization of the snowfall effect can influence better systems optimization for climates experiencing snowfall. Future work is also needed to investigate system design to better utilize albedo augmentation techniques.

\section{Acknowledgements}

The authors would like to acknowledge the work of $\mathrm{H}$. McLaren, J. Fairborn, Q. Bentley, D. Carter and A. Babasola and the support of the Sustainable Energy Applied Research Centre at St. Lawrence College, and to the forward-looking industry partners of this project who made it possible. In addition we acknowledge support from the Natural Sciences and Engineering Research Council of Canada and a Social Sciences and Humanities Research Council of Canada Strategic Research Grant on Environmental Issues. In addition, the support of the on-line communities for both Matlab and $\mathrm{AT}_{\mathrm{E} X}$. 


\section{References}

\section{References}

Andrews, R., Pearce, J.M., 2012. The effect of spectral albedo on amorphous silicon and crystalline silicon solar photovoltaic device performance. Under Review .

Andrews, R., Pearce, J.M., Pollard, A., 2012. Improved parametric empirical determination of module short circuit current for modelling and optimization of solar photovoltaic systems. Solar Energy 86, 2240-2254.

Becker, G., Schiebelserger, B., Weber, W., Schumacher, J., Zehner, M., Wortuba, G., Vodermayer, C., 2008. Energy yields of PV systems- comparison of simulation and reality., Valencia, Spain.

Branker, K., Pathak, J., Pearce, J.M., 2011a. A review of solar photovoltaic levelized cost of electricity. Renewable \& Sustainable Energy Reviews 15, 4470-4482.

Branker, K., Shackles, E., Pearce, J.M., 2011b. Peer-to-peer financing mechanisms to accelerate renewable energy deployment. Journal of Sustainable Finance \& Investment 1, 138-155.

Brench, B.L., 1979. Snow-covering effects on the power output of solar photovoltaic arrays. DOE DE-AC02-76ET20279

Curl, H., Hardy, J.T., Ellermeier, R., 1972. Spectral absorption of solar radiation in alpine snowfields. Ecology 53, 1189-1194.

EnvironmentCanada, 2012. Kingston climate weather station. National Climate Data and Information Archive (NCDIA) WMO ID: 71820 , Climate ID:6104142.

Fabero, F., Chenlo, F., 1991. Variance in the solar spectrum with the position of the receiver surface during the day for PV applications, in: Photovoltaic Specialists Conference, 1991., Conference Record of the Twenty Second IEEE, pp. $812-817$ vol.1.

Gardner, A.S., Sharp, M.J., 2010. A review of snow and ice albedo and the development of a new physically based broadband albedo parameterization. Journal of Geophysical Research 115.

Giddings, J.C., LaChapelle, E., 1961. Diffusion theory applied to radiant energy distribution and albedo of snow. Journal of Geophysical Research 66, PP. 181-189.

Guizar-Sicairos, M., Thurman, S.T., Fienup, J.R., 2008. Efficient subpixel image registration algorithms. Optics Letters 33, 156158.

Kako, T., Nakajima, A., Irie, H., Kato, Z., Uematsu, K., Watanabe, T., Hashimoto, K., 2004. Adhesion and sliding of wet snow on a super-hydrophobic surface with hydrophilic channels. Journal of Materials Science 39, 547-555.

Kenny, R., Law, C., Pearce, J., 2010. Towards real energy economics: Energy policy driven by life-cycle carbon emission. Energy Policy 38, 1969-1978.

King, D.L., Boyson, W.E., Kratochvil, J.A., 2004. Photovoltaic array performance model. Sandia SAND2004-3535.

Laleman, R., Albrecht, J., Dewulf, J., 2011. Life cycle analysis to estimate the environmental impact of residential photovoltaic systems in regions with a low solar irradiation. Renewable and Sustainable Energy Reviews 15, 267-281.

Mani, M., Pillai, R., 2010. Impact of dust on solar photovoltaic (PV) performance: Research status, challenges and recommendations. Renewable and Sustainable Energy Reviews 14, 3124-3131.

Marion, B., Adelstein, J., Boyle, K., Hayden, H., Hammond, B., Fletcher, T., Canada, B., Narang, D., Kimber, A., Mitchell, L., Rich, G., Townsend, T., 2005. Performance parameters for Grid-Connected PV systems. 31st IEEE Photovoltaics Specialists Conference and Exhibition

Mondol, J.D., Yohanis, Y.G., Norton, B., 2009. Optimising the economic viability of grid-connected photovoltaic systems. Applied Energy 86, 985-999.

Nieuwlaar, E., Alsema, E., 1997. Environmental Aspects of PV Power Systems. Technical Report 97072. Utrecht University, IEA PVPS Task 1 Workshop. Utrecht, The Netherlands.

Nobuyuki, O., 1979. A threshold selection method from Gray-Level histograms. Systems, Man and Cybernetics, IEEE Transactions on $9,62-66$

O'Neill, A., Gray, D.M., 1972. Solar radiation penetration through snow. Symposia on the Role of Snow and Ice in hydrology.
Parida, B., Iniyan, S., Goic, R., 2011. A review of solar photovoltaic technologies. Renewable and Sustainable Energy Reviews 15, 1625-1636.

Pearce, J., Denkenberger, D., Zeilonka, H., 2009. Energy Conservation measures as Investments. Nova Science Publishers Inc. chapter 2. Energy Conservation: New Research.

Pearce, J.M., 2002. Photovoltaics - a path to sustainable futures. Futures 34, 663-674.

Pearce, J.M., Babasola, A., Andrews, R., 2012. Open solar photovoltaic systems optimization. Proceedings of the 16th Annual National Collegiate Inventors and Innovators Alliance Conference, Open 2012

Pfister, R., Schneebeli, M., 1999. Snow accumulation on boards of different sizes and shapes. Hydrological Processes 13, 2345-2355.

Ren, H., Gao, W., Ruan, Y., 2009. Economic optimization and sensitivity analysis of photovoltaic system in residential buildings. Renewable Energy 34, 883-889.

Ross, M.M.D., 1995. Snow and ice accumulation on photovoltaic arrays: An assessment of the TN conseil passive melting technology, report\# EDRL 95-68 (TR), energy diversification research laboratory, CANMET. Natural Resources Canada, Varennes, September.

SolarBuzz, 2010. MarketBuzz. Technical Report.

Thevenard, D., 2006. Ground reflectivity in the context of building energy simulation. Energy \& Buildings 38, 972-980.

Thevenard, D., Driesse, A., Turcotte, D., Poissant, Y., 2010. Uncertainty in Long-Term Photovoltaic Yield Predictions. Technical Report 2010-122 (RP-TEC) 411-IEARES. CanmetENERGY, Natural Resources Canada.

Townsend, T., Powers, L., 2011. Photovoltaics and snow: An update from two winters of measurements in the sierra, 37th IEEE PVSC.

Warren, S.G., 1972. Optical properties of snow. Reviews of Geophysics 20, PP. 67-89.

Wirth, G., Schroedter-Homscheidt, M., Zehner, M., Becker, G., 2010. Satellite-based snow identification and its impact on monitoring photovoltaic systems. Solar Energy 84, 215-226.

Wolf, M., Rauschenbach, H., 1963. Series resistance effects on solar cell measurements. Advanced Energy Conversion 3, 455-479.

Yoshio, H., Toshiyuki, S., Makoto, T., 1999. Snow fall on the photovoltaic array and snow sliding condition. Journal of Snow Engineering of Japan 15, 15-16.

Yoshioka, K., Saitoh, T., Yamamura, T., 2003. Performance monitoring of a building-integrated photovoltaic system in an urban area, in: Photovoltaic Energy Conversion, 2003. Proceedings of 3rd World Conference on, pp. 2362-2365 Vol.3. 